\title{
Interplate fault slip along the Japan Trench before the occurrence of the 2011 off the Pacific coast of Tohoku Earthquake as inferred from GPS data
}

\author{
Hisashi Suito, Takuya Nishimura, Mikio Tobita, Tetsuro Imakiire, and Shinzaburo Ozawa \\ Geography and Crustal Dynamics Research Center, Geospatial Information Authority of Japan, Kitasato 1, Tsukuba 305-0811, Japan
}

(Received April 7, 2011; Revised June 21, 2011; Accepted June 30, 2011; Online published September 27, 2011)

\begin{abstract}
A sequence of $M 7$-class interplate earthquakes and transient postseismic slips following each of these earthquakes occurred along the Japan Trench before the occurrence of the giant earthquake on March 11, 2011. Continuous GPS data detected a significant postseismic deformation with displacements that were much larger than that of the coseismic offset. Moreover, the geodetic inversion results using these observations revealed that the total moment released by these transient slips was much larger than the coseismic ones. This differs from our understanding of the postseismic process that the postseismic deformation and slip are smaller than the coseismic ones. These transient processes may help us understand not only the postseismic process but also the pre-seismic signals indicating the occurrence of the giant earthquake.
\end{abstract}

Key words: Interplate fault slip, postseismic deformation, the 2011 off the Pacific coast of Tohoku Earthquake, pre-seismic signal, the Japan Trench.

\section{Introduction}

A giant earthquake with a moment magnitude of $9.0 \mathrm{oc}-$ curred at 14:46 (JST) on March 11, 2011, along the Japan Trench (Fig. 1(a)). This giant earthquake generated a huge tsunami which caused significant damage. Many $M 7-$ class interplate earthquakes have occurred along the Japan Trench because of the subduction of the Pacific plate beneath northeast Japan at rates of 7.9-9.2 cm/yr (e.g., Sella et al., 2002). A sequence of $M 7$-class earthquakes occurred in the Fukushima-oki region in 1938 (Abe, 1977). A characteristic earthquake $(M=7.4)$ periodically occurred with a recurrence interval of about 37 years in the Miyagi-oki (ERC, 2000). The occurrence of large aseismic events following the $M 7$-class earthquakes in 1989 and 1992 are reported in the northern Sanriku-oki region (Kawasaki et al., 2001). However, no historical records of $M>8.5$ earthquakes along the Japan Trench have been reported since the 11th century. In this tectonic setting, a sequence of $M 7$-class interplate earthquakes and transient postseismic slips following each earthquake occurred along the Japan Trench: (1) August 16, 2005, Miyagi-ken oki earthquake $\left(M_{\mathrm{j}} 7.2\right)$; (2) May 8, 2008, Ibaraki-ken oki earthquake $\left(M_{\mathrm{j}} 7.0\right)$; (3) July 19 , 2008, Fukushima-ken oki earthquake $\left(M_{\mathrm{j}} 6.9\right)$; (4) March 14, 2010, Fukushima-ken oki earthquake $\left(M_{\mathrm{j}} 6.7\right)$; and (5) March 9, 2011, Sanriku oki earthquake $\left(M_{\mathrm{j}} 7.3\right)$. Figure 1(a) shows these occurrences on a map. In this paper, we report the preliminary results of our study of this sequence of interplate fault slips, before the occurrence of the giant earthquake, based on GPS data;

Copyright (c) The Society of Geomagnetism and Earth, Planetary and Space Sciences (SGEPSS); The Seismological Society of Japan; The Volcanological Society of Japan; The Geodetic Society of Japan; The Japanese Society for Planetary Sciences; TERRAPUB.

doi:10.5047/eps.2011.06.053 we discuss the long-term pre-seismic signals of the giant earthquake.

\section{Data}

A nation-wide continuous GPS network, GEONET (GPS Earth Observation Network System), operated by the Geospatial Information Authority (GSI) of Japan, includes more than 1300 stations spread over the entire region of Japan. GEONET data are routinely analyzed using the BERNESE Ver. 5.0 software and the IGS (International GNSS Service) final ephemeris. The daily coordinates of the GPS stations are published as "F3 solutions" (Nakagawa et al., 2009). Here, we used the daily coordinates with respect to the site 950154 (Iwasaki, see Fig. 1(a)). Annual, semi-annual, and linear-trend components in the GPS time series were estimated by least-square fitting for the period from January 1, 1997, to January 1, 2002, when there were no abnormal events. Subsequently, we removed them from the original time series. Note that coseismic offsets by large earthquakes are not eliminated in this time series, including those of the September 26, 2003, Tokachi oki earthquake $\left(M_{\mathrm{j}} 8.0\right)$.

\section{Results and Discussions \\ 3.1 Time series}

The time series of the GPS data in the east-west component clearly reveals coseismic offset and subsequent transient deformation at each earthquake (Fig. 1(b)). There was no significant subsidence or uplift signals in the vertical component except for the coseismic subsidence by the 2005 Miyagi earthquake, which is not displayed here. The westward step in 2008 at the stations 950172, 950175, and 960550 is a coseismic offset associated with the June 14, 2008 , Iwate-Miyagi Nairiku earthquake $\left(M_{\mathrm{j}} 7.2\right)$, which occurred in the inland shallow crust (Fig. 1(a)). We do not 

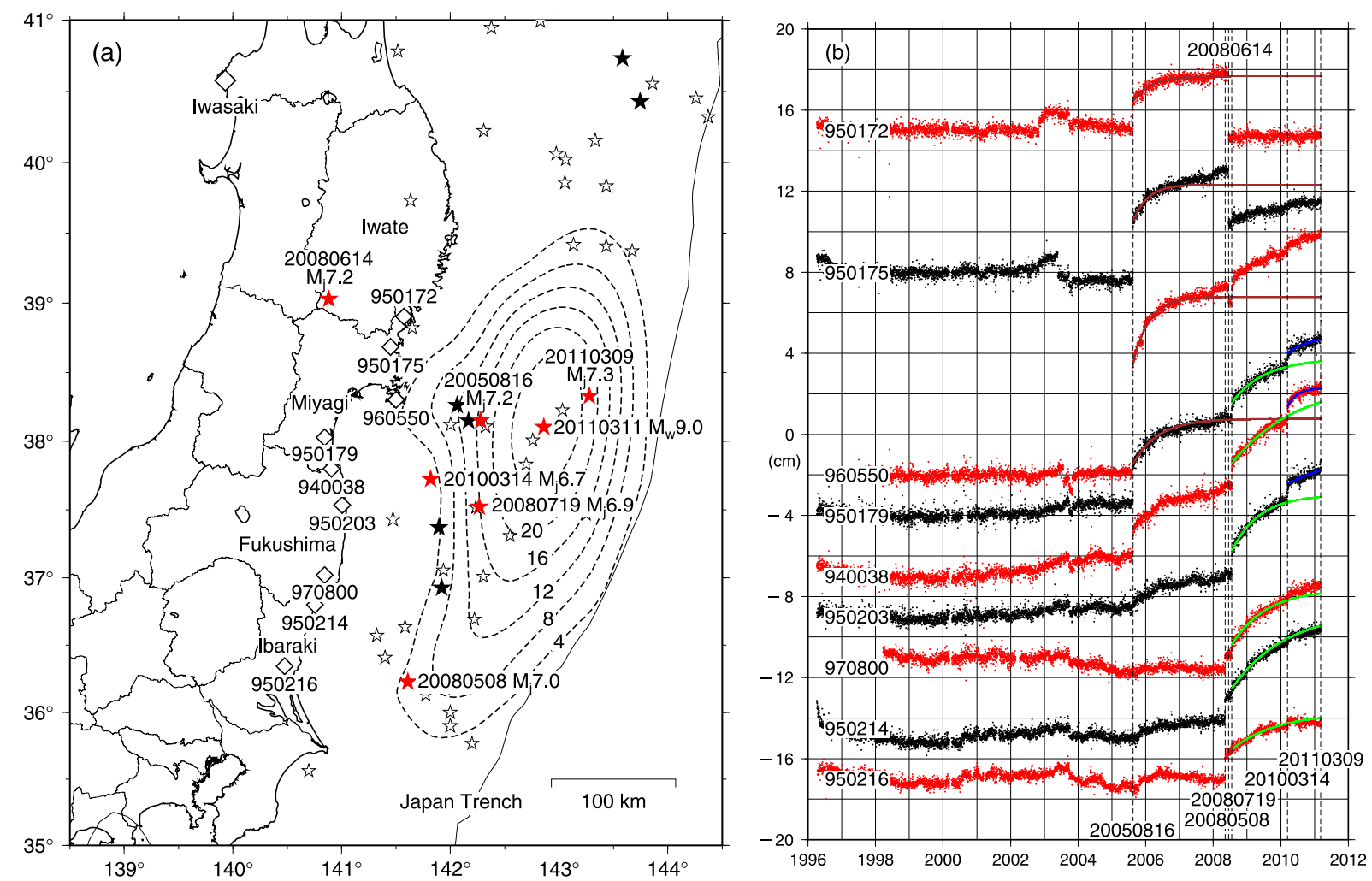

Fig. 1. Location map of study area and time series of GPS data. (a) Study area with epicenters, mentioned in this study, indicated by red stars. White stars represent the epicenters of large $(M \geq 6.8)$ earthquakes that have occurred since 1923, and earthquakes with $M>7.4$ are marked with black stars. White diamonds represent the sites whose time series are shown in (b). Broken lines indicate the coseismic slip distribution, with a contour interval of $4 \mathrm{~m}$ of the 2011 Tohoku earthquake (Ozawa et al., 2011). (b) Transient time series of E-W component at selected stations whose location is shown in (a). Exponential functions are also indicated in brown, green, and blue lines, which correspond to the 2005 Miyagi, 2008 Fukushima, and 2010 Fukushima earthquakes, respectively, at the stations mentioned in the text. Vertical broken lines indicate the date of the earthquakes whose epicenters are shown in (a) as red stars.

discuss the deformations associated with this earthquake.

In the case of the 2005 Miyagi earthquake, postseismic transient deformation decayed rapidly with time and ended in the middle of 2007, as is seen at the sites 950172, 950175, 960550 , and 950179 . Its duration seems to be about 2 years, as Miura et al. (2006) reported. We refer to this event as a reference of postseismic deformation produced by an afterslip in this study. A number of studies have reported that the postseismic signals produced by an afterslip rapidly decay with time and the amount of displacement is less than or equal to the coseismic offset, although the decay time and duration of the signal are different for each earthquake and may also depend on its mechanisms (e.g., Heki et al., 1997; Gahalaut et al., 2008; Perfettini et al., 2010). On the other hand, large transient displacements were seen after the 2008 Ibaraki earthquake at the stations 970800, 950214, and 950216, and after the 2008 and 2010 Fukushima earthquakes at the stations 950179, 940038, and 950203, located in Fukushima and Ibaraki prefectures (Fig. 1). As described in greater detail in the next section, it is noted here that the total transient deformations are extremely large compared to those of the coseismic offset at these stations. Moreover the decay-time constant, assuming exponential decay at these stations, is estimated to be more than 300 days for the 2008 Ibaraki, and the 2008 and 2010 Fukushima earthquakes. This constant is much larger than in the case of the 2005 Miyagi earthquake, which is estimated to be about
200 days or less at stations 950172, 950175, 960550, and 950179 (Fig. 1(b)).

\subsection{Coseismic and postseismic deformations}

Based on these time series, we look into the spatial distribution of each coseismic and postseismic deformation (Fig. 2). The duration of each postseismic period is different in each panel in Fig. 2; details are given in the figure caption and Table 1 . The coseismic deformation is concentrated near the epicenter but the postseismic deformation is distributed in a broader region. The maximum postseismic displacement is smaller than the coseismic one in the case of the 2005 Miyagi earthquake (Fig. 2(a)). Conversely, the total postseismic deformations following the 2008 and 2010 Fukushima earthquakes are much larger than the coseismic deformations. For example, the transient displacement following the 2010 Fukushima earthquake is more than $10 \mathrm{~mm}$ at the stations along the Pacific coast (Fig. 2(d)), although the coseismic displacement is less than $5 \mathrm{~mm}$. The total time period of this transient deformation is only about 1 year, which seems to continue until the March 9, 2011, Sanriku oki earthquake $\left(M_{\mathrm{j}} 7.3\right)$ (see Fig. 1(b)).

\subsection{Estimated coseismic and postseismic slip}

Using these displacement data, we performed the inversion method devised by Yabuki and Matsu'ura (1992) to estimate the fault slip of this sequence of earthquakes and postseismic events on the plate interface. The results are shown in Fig. 2 with the observed horizontal displace- 

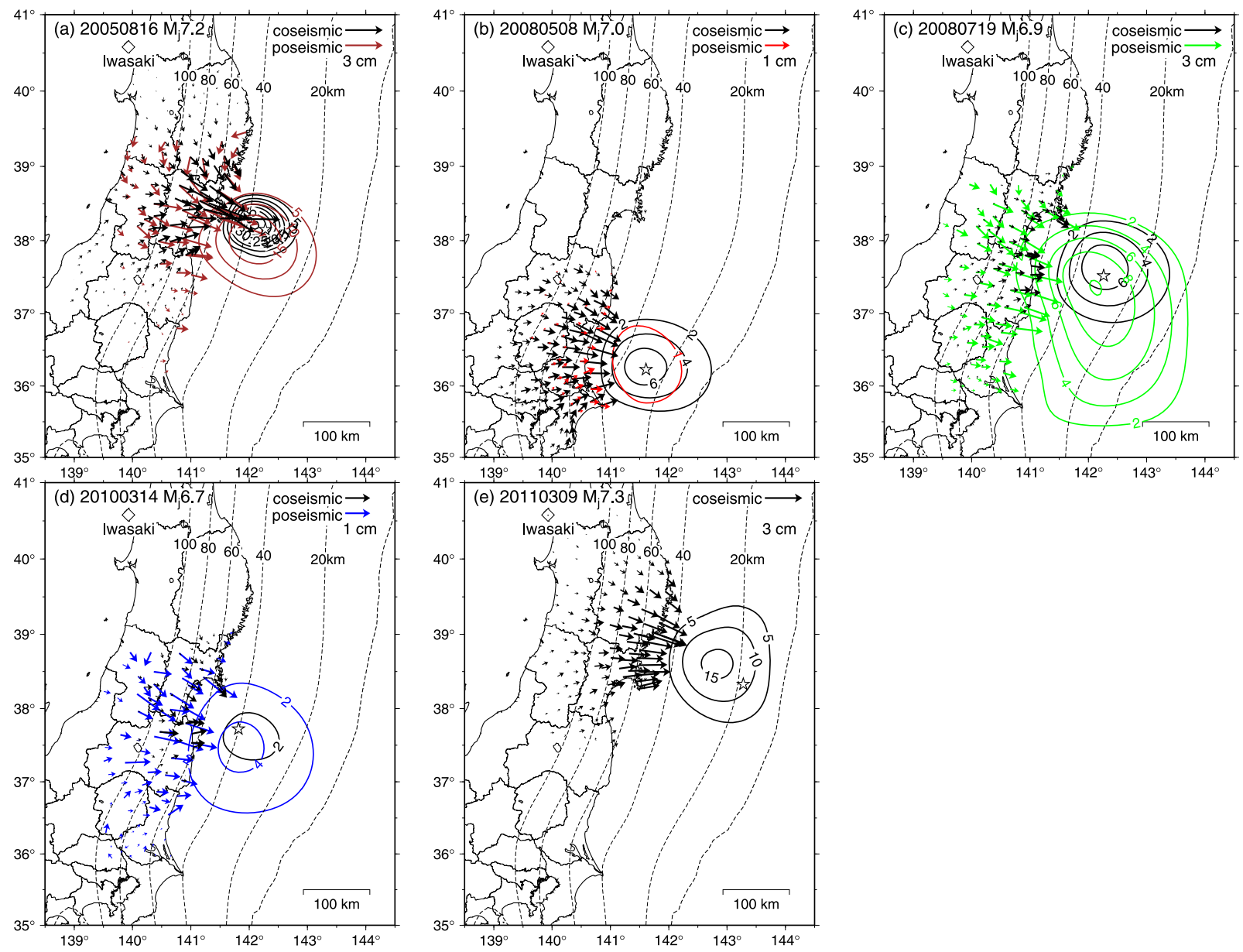

Fig. 2. Coseismic and postseismic observed displacements and estimated slip distribution. (a) 2005 Miyagi-ken oki earthquake $M_{\mathrm{j}} 7.2$ (August 16, 2005); (b) 2008 Ibaraki-ken oki earthquake $M_{\mathrm{j}} 7.0$ (May 8, 2008); (c) 2008 Fukushima-ken oki earthquake $M_{\mathrm{j}} 6.9$ (July 19, 2008); and (d) 2010 Fukushima-ken oki earthquake $M_{\mathrm{j}} 6.7$ (March 14, 2010). (e) Coseismic observed displacements and estimated slip distribution of the 2011 Sanriku oki earthquake $M_{\mathrm{j}} 7.3$ (March 9, 2011). Black arrows and contours represent coseismic displacements and slip, and colored ones represent postseismic displacements and slip in each panel, respectively. The contour interval of each coseismic and postseismic slip is $2 \mathrm{~cm}$ in panels (b), (c), and (d), $5 \mathrm{~cm}$ in panels (a) and (e). Also, the arrows scale is $3 \mathrm{~cm}$ in panels (a), (c), and (e) and $1 \mathrm{~cm}$ in panels (b) and (d). Broken lines indicate isodepth contours of the plate interface with 20-km intervals (Nakajima and Hasegawa, 2006). Stars indicate the epicenter of each earthquake. Postseismic period is (a) 2.72 years; 20050817-20080507, (b) 0.19 years; 20080509-20080718, (c) 1.65 years; 20080720-20100313, and (d) 0.98 years; 20100315-20110308 (see also Table 1).

Table 1. Estimated moments of coseismic and postseismic slip in this study.

\begin{tabular}{|c|c|c|c|c|c|}
\hline Earthquake name & Miyagi & Ibaraki & Fukushima & Fukushima & Sanriku \\
\hline Year & 2005 & 2008 & 2008 & 2010 & 2011 \\
\hline Date & 0816 & 0508 & 0719 & 0314 & 0309 \\
\hline$M_{\mathrm{j}}$ & 7.2 & 7.0 & 6.9 & 6.7 & 7.3 \\
\hline \multicolumn{6}{|l|}{ Coseismic } \\
\hline Moment $\left(\times 10^{19} \mathrm{~N} \mathrm{~m}\right)$ & 6.60 & 3.84 & 4.20 & 1.64 & 10.59 \\
\hline$M_{\mathrm{w}}$ & 7.15 & 6.99 & 7.02 & 6.74 & 7.28 \\
\hline \multicolumn{6}{|l|}{ Postseismic } \\
\hline Period (years) & 2.72 & 0.19 & 1.65 & 0.98 & - \\
\hline Moment $\left(\times 10^{19} \mathrm{~N} \mathrm{~m}\right)$ & 12.19 & 2.02 & 14.96 & 5.06 & - \\
\hline$M_{\mathrm{w}}$ & 7.32 & 6.80 & 7.38 & 7.07 & - \\
\hline
\end{tabular}

ments. The estimated postseismic slip is distributed over a broad area compared to the coseismic slip distribution in all events. The peak locations of the coseismic and postseismic slips are nearly identical in most cases. Previous studies reported that the location of the maximum slip of the coseismic and postseismic areas is not in the same place. Most of the postseismic slip occurred on the deeper extent or sur- rounding area of the main rupture at the plate interface for $M 8$ class earthquakes in the Japan Trench (e.g., Yagi et al., 2003; Ozawa et al., 2004) and for $M 8 \sim 9$ class events in other subduction zones (e.g., Perfettini et al., 2010; Vigny et al., 2011). Baba et al. (2006) reported that postseismic slip was estimated on the surrounding area including that at the same depth as the main rupture of the 2003 Tokachi-oki 
earthquake using the offshore geodetic data.

Our synthetic test of the case that postseismic slip distributes around the coseismic slip shows that the coseismic slip is reasonably well resolved by the geodetic data. In the case of the postseismic slip, deep slip near or beneath the land is well resolved when the data include enough signals in the vertical component. However, it is undeniable that the land geodetic data do not resolve shallow off-shore slip on the plate interface. Because the observed horizontal displacements are small, the signal-to-noise ratio of the used data is low. And there are no clear vertical signals in our data. Consequently, the resolving power of our inversion is poor and this may affect out results regarding the distribution of the coseismic and postseismic slip. Therefore, we emphasize the ratio of moment release between coseismic and postseismic slip, rather than their spatial distribution, in this study.

The released moment by each postseismic slip is also larger than the coseismic slip (see Table 1). For example, it is more than three and a half times larger than the 2008 Fukushima earthquake, though the postseismic slip following this earthquake is included in the postseismic slip induced by the 2008 Ibaraki earthquake, which occurred just two months earlier and was located $200-\mathrm{km}$ south from the epicenter of the 2008 Fukushima earthquake. However, it should be noted that the moment released by this postseismic slip is larger than the sum of the coseismic moments of these two earthquakes. Furthermore, the postseismic signals apparently did not end in this time period, because the next earthquake occurred before the end of the postseismic signal (see Fig. 1(b)).

\subsection{Interpretation of sequence events}

Five $M 7$-class interplate earthquakes occurred before the $M_{\mathrm{w}} 9.0$ giant earthquake, as we have described in the foregoing. The total moments released by the interplate earthquakes and postseismic slips are $26.9 \times 10^{19} \mathrm{~N}$ m and $34.2 \times 10^{19} \mathrm{~N} \mathrm{~m}$, respectively. This is only $1.5 \%$ of that of the $M_{\mathrm{w}} 9.0$ giant earthquake (see Table 1 ).

Our understanding of the postseismic slip following the coseismic rupture is that of a strain-release process of the remnant strain that is not released by the coseismic rupture. Therefore, the postseismic slip proceeds on the deeper part or adjacent to the main rupture area, and the moment release is equal or less than the coseismic. In addition, the observed postseismic signal reveals a strong reduction with time.

Based on our understanding of the postseismic process, we look again into the sequence of the interplate fault slip. The postseismic process of the three earthquakes in 2008 and 2010 seems to be slightly different from the 2005 Miyagi earthquake case. Certainly, the postseismic signals following these three earthquakes decay with time (Fig. 1(b)). However, the decay-time constant is much longer than that of the 2005 Miyagi earthquake case, and the total postseismic displacement is much larger than the coseismic displacement even though the postseismic process does not appear to end in each period (Figs. 1(b) and 2). Moreover, the moment released by the postseismic slip is also larger than that of the coseismic rupture in each earthquake (Table 1).

Strong interplate coupling has been estimated along the
Japan Trench using GPS data and this region corresponded to the $M 7 \sim 8$ class earthquake rupture area (Nishimura et al., 2004; Suwa et al., 2006; Hashimoto et al., 2009). However, the average strain rate released in historical earthquakes is considerably lower than the strain accumulation rate estimated from contemporary deformation. An aseismic slip, including an afterslip, has been suggested as a possible mechanism for the accumulated strain release in the Japan Trench (e.g., Heki et al., 1997; Kawasaki et al., 2001). In the Sanriku-oki region, Kawasaki et al. (2001) reported that a large moment was released by an aseismic slip following the earthquakes, including the 1989 and 1992 Sanriku-oki earthquakes. However, the duration of these aseismic events is less than a few weeks.

Considering these temporal and spatial differences from the postseismic process and strain budget in the Japan Trench, we may interpret these sequence events not only as part of the postseismic strain-release process but also as the preparation or pre-seismic signal of the giant earthquake. Recently, Hori and Miyazaki (2011) numerically simulated earthquake cycles in which several $M 7$ events occur between recurrences of $M 9$ events. They reported that postseismic slip following the $M 7$ events became larger and wider in the later part of the $M 9$ earthquake cycle. However, even if this interpretation is correct, it is difficult to distinguish between the postseismic and pre-seismic process based on the data before the 2011 Tohoku earthquake.

\section{Conclusion}

Based on the GPS data and geodetic inversion, a sequence of $M$ 7-class interplate earthquakes and subsequent transient events prior to the giant earthquake were investigated to discuss the long-term pre-seismic signals of the giant earthquake. The main results of this paper is that the observed postseismic deformations and the estimated moment released by the transient slip following the $M 7$-class earthquakes, which occurred in 2008 and 2010, are much larger than the coseismic ones. These results are different from our understanding of the postseismic process as the postseismic deformation and slip are smaller than that of the main rupture. One of the possible interpretations is that these sequence events provide insights not only on the postseismic process but also on the pre-seismic signal of the giant earthquake.

Acknowledgments. We appreciate Dr. Miyazaki and an anonymous referee for useful comments. We also thank the Japan Meteorological Agency for providing their earthquake catalogue. All the figures were created with the GMT (Generic Mapping Tools) software by Paul Wessel and Walter H. F. Smith.

\section{References}

Abe, K., Tectonic implications of the large Shioya-oki earthquake of 1938, Tectonophysics, 41, 269-289, 1977.

Baba, T., K. Hirata, T. Hori, and H. Sakaguchi, Offshore geodetic data conducive to the estimation of the afterslip distribution following the 2003 Tokachi-oki earthquake, Earth Planet. Sci. Lett., 241, 281-292, 2006.

Earthquake Research Committee (ERC), Long-term forecast of Miyagioki earthquake, The Headquarters for Earthquake Research Promotion, http://www.jishin.go.jp/main/chousa/00nov4/miyagi.htm, 2000 (in Japanese).

Gahalaut, V. K., S. Jade, J. K. Catherine, R. Gireesh, M. B. Ananda, P. D. 
Kumar, M. Narsaiah, S. S. H. Jafri, A. Ambikapathy, A. Bansa, R. K. Chadha, D. C. Gupta, B. Nagarajan, and S. Kumar, GPS measurements of postseismic deformation in the Andaman-Nicobar region following the giant 2004 Sumatra-Andaman earthquake, J. Geophys. Res., 113, B08401, doi:10.1029/2007JB005511, 2008.

Hashimoto, C., A. Noda, T. Sagiya, and M. Matsu'ura, Interplate seismogenic zones along the Kuril-Japan trench inferred from GPS data inversion, Nature Geosci., 2, 141-144, doi:10.1038/ngeo421, 2009.

Heki, K., S. Miyazaki, and H. Tsuji, Silent fault slip following an interplate thrust earthquake at the Japan Trench, Nature, 386, 595-597, 1997.

Hori, T. and S. Miyazaki, A possible mechanism of $M 9$ earthquake generation cycles in the area of repeating $M 7 \sim 8$ earthquakes surrounded by aseismic sliding, Earth Planets Space, 63, this issue, 773-777, 2011.

Kawasaki, I., Y. Asai, and Y. Tamura, Space-time distribution of interplate moment release including slow earthquakes and the seismo-geodetic coupling in the Sanriku-oki region along the Japantrench, Tectonophysics, 330, 267-283, 2001.

Miura, S., T. Iinuma, S. Yui, N. Uchida, T. Sato, K. Tachibara, and A. Hasegawa, Co- and post-seismic slip associated with the 2005 Miyagioki earthquake (M 7.2) as inferred from GPS data, Earth Planets Space, 58, 1567-1572, 2006.

Nakagawa, H., T. Toyofuku, K. Kotani, B. Miyahara, C. Iwashita, S. Kawamoto, Y. Hatanaka, H. Munekane, M. Ishimoto, T. Yutsudo, N. Ishikura, and Y. Sugawara, Development and validation of GEONET new analysis strategy (Version 4), J. Geogr. Surv. Inst., 118, 1-8, 2009 (in Japanese).

Nakajima, J. and A. Hasegawa, Anomalous low-velocity zone and linear alignment of seismicity along it in the suducted Pacific slab beneath Kanto, Japan: Reactivation of subducted fracture zone?, Geophys. Res. Lett., 33, L16309, doi:10.1029/2006GL026773, 2006.

Nishimura, T., T. Hirasawa, S. Miyazaki, T. Sagiya, T. Tada, S. Miura, and K. Tanaka, Temporal change of interplate coupling in northeastern Japan during 1995-2002 estimated from continuous GPS observations, Geophys. J. Int., 157, 901-916, 2004.

Ozawa, S., M. Kaidzu, M. Murakami, T. Imakiire, and Y. Hatanaka, Co- seismic and postseismic crustal deformation after the $M_{\mathrm{w}} 8$ Tokachi-oki earthquake in Japan, Earth Planets Space, 56, 675-680, 2004.

Ozawa, S., T. Nishimura, H. Suito, T. Kobayashi, M. Tobita, and T. Imakiire, Coseismic and postseismic slip of the 2011 magnitude-9 TohokuOki earthquake, Nature, doi:10.1038/nature10227, 2011.

Perfettini, H., J.-P. Avouac, H. Tavera, A. Kositsky, J.-M. Nocquet, F. Bondoux, M. Chlieh, A. Sladen, L. Audin, D. L. Farber, and P. Soler, Seismic and aseismic slip on the Central Peru megathrust, Nature, 465, doi:10.1038/nature09062, 2010.

Sella, G. F., T. H. Dixon, and A. Mao, REVEL: A model for recent plate velocities from space geodesy, J. Geophys. Res., 107(B4), 2081, doi:10.1029/2000JB000033, 2002.

Suwa, Y., S. Miura, A. Hasegawa, T. Sato, and K. Tachibara, Interplate coupling beneath NE Japan inferred from three-dimensional displacement field, J. Geophys. Res., 111, B04402, doi:10.1029/2004JB003203, 2006.

Vigny, C., A. Socquet, S. Peyra, J. C. Ruegg, M. Metois, R. Madariaga, S. Morvan, M. Lancieri, R. Lacassin, J. Campos, D. Carrizo, M. BejarPizarro, S. Barrientos, R. Armijo, C. Aranda, M. C. Valderas-Bermejo, I. Ortega, F. Bondoux, S. Baize, H. Lyon-Caen, A. Pavez, J. P. Vilotte, M. Bevis, B. Brooks, R. Smalley, H. Parra, J. C. Baez, M. Blanco, S. Climbaro, and E. Kendrick, The $2010 M_{\mathrm{w}} 8.8$ Maule megathrust earthquake of central Chile, monitored by GPS, Science, 332, 14171421, doi:10.1126/science.1204132, 2011.

Yabuki, T. and M. Matsu'ura, Geodetic inversion using a Bayesian Information criteria for spatial distribution of fault slip, Geophys. J. Int., 109, 363-375, 1992.

Yagi, Y., M. Kikuchi, and T. Nishimura, Co-seismic slip, postseismic slip, and largest aftershock associated with the 1994 Sanriku-haruka-oki, Japan, earthquake, Geophys. Res. Lett., 30, 2177, doi:10.1029/2003GL018189, 2003.

H. Suito (e-mail: suito@gsi.go.jp), T. Nishimura, M. Tobita, T. Imakiire, and S. Ozawa 